\title{
Fatty Acid Biosynthesis Inhibition Increases Reduction Potential in Neuronal Cells under Hypoxia
}

\author{
Stephen A. Brose, Svetlana A. Golovko and Mikhail Y. Golovko* \\ Department of Biomedical Sciences, University of North Dakota, Grand Forks, ND, USA
}

Recently, we have reported a novel neuronal specific pathway for adaptation to hypoxia through increased fatty acid (FA) biosynthesis followed by esterification into lipids. However, the biological role of this pathway under hypoxia remains to be elucidated. In the presented study, we have tested our hypothesis that activation of FA synthesis maintains reduction potential and reduces lactoacidosis in neuronal cells under hypoxia. To address this hypothesis, we measured the effect of FA synthesis inhibition on $\mathrm{NADH}_{2}^{+} / \mathrm{NAD}^{+}$and $\mathrm{NADPH}_{2}^{+} / \mathrm{NADP}^{+}$ratios, and lactic acid levels in neuronal SH-SY5Y cells exposed to normoxic and hypoxic conditions. FA synthesis inhibitors, TOFA (inhibits Acetyl-CoA carboxylase) and cerulenin (inhibits FA synthase), increased $\mathrm{NADH}_{2}^{+} / \mathrm{NAD}^{+}$

OPEN ACCESS

Edited by:

Natalia N. Nalivaeva,

University of Leeds, UK

Reviewed by:

Luigi Bubacco,

University of Padua, Italy William Griffiths,

Swansea University, UK Sergey Khasabov,

University of Minnesota, USA

*Correspondence:

Mikhail Y. Golovko

mikhail.golovko@med.und.edu

Specialty section: This article was submitted to

Neurodegeneration,

a section of the journal

Frontiers in Neuroscience

Received: 13 September 2016 Accepted: 11 November 2016

Published: 30 November 2016

Citation:

Brose SA, Golovko SA and

Golovko MY (2016) Fatty Acid

Biosynthesis Inhibition Increases

Reduction Potential in Neuronal Cells

under Hypoxia.

Front. Neurosci. 10:546.

doi: 10.3389/fnins.2016.00546 and $\mathrm{NADPH}_{2}^{+} / \mathrm{NADP}^{+}$ratios under hypoxia. Further, FA synthesis inhibition increased lactic acid under both normoxic and hypoxic conditions, and caused cytotoxicity under hypoxia but not normoxia. These results indicate that FA may serve as hydrogen acceptors under hypoxia, thus supporting oxidation reactions including anaerobic glycolysis. These findings may help to identify a radically different approach to attenuate hypoxia related pathophysiology in the nervous system including stroke.

\section{Keywords: hypoxia, reduction and oxidation potential, lactic acid, NAD, NADP, fatty acids, lipid biosynthesis}

\section{INTRODUCTION}

Despite the significant role for brain hypoxia in the development of many of pathophysiological conditions including stroke, traumatic brain injury, tumorigenesis, aging, and neurodegenerative diseases (Gallagher and Hackett, 2004; Wilson et al., 2009; Raymond et al., 2011; Clambey et al., 2012; Kirby et al., 2012; Lin et al., 2013), biochemical mechanisms for adaptation to hypoxia are still poorly understood. Recently, we have discovered a previously unknown and neuron-specific mechanism for utilizing anaerobic metabolism during hypoxia. We have found that hypoxicstressed neurons have a unique response of dramatically increased fatty acid (FA) synthesis from glutamine and glutamate (Gln/Glu) (Brose et al., 2014). However, the biochemical significance of this pathway in neuronal adaptation to hypoxia is unknown. Previously, we have hypothesized a few mechanisms to address the importance for activated FA synthesis from Gln/Glu under hypoxia (Brose et al., 2014) including balancing Glu levels, protection against oxidative stress, and maintaining reduction potential with support of anaerobic glycolysis. In the present study,

Abbreviations: FA, fatty acids; Gln, glutamine; Glu, glutamate; LDH, lactate dehydrogenase; MS, mass spectrometry; UPLC, ultra-pressure liquid chromatography. 
we have tested one of these hypotheses that FA SYNTHESIS supports anaerobic metabolism under hypoxia through accepting hydrogen from reduced cofactors $\left(\mathrm{NADH}_{2}^{+}, \mathrm{NADPH}_{2}^{+}, \mathrm{FADH}_{2}\right)$, thus maintaining reduction potential.

Under hypoxia, hydrogen accumulates on reduced cofactors $\left(\mathrm{NADH}_{2}^{+}, \mathrm{NADPH}_{2}^{+}, \mathrm{FADH}_{2}\right.$; Garofalo et al., 1988; ObiTabot et al., 1993; Foster et al., 2005), due to the decrease in $\mathrm{O}_{2}$ as its final acceptor. This results in a decreased ATP production through oxidative phosphorylation, and an increased ratio of reduced/oxidized cofactors in the cell and therefore, an increased reduction potential. The altered reduction potential has several devastating effects on cells including lactate accumulation as an alternative $\mathrm{H}_{2}$ acceptor and subsequent pH drop (Payen et al., 1996; Malisza et al., 1999; Zhang et al., 2006), increased formation of reactive oxygen species which damage lipids, proteins, and DNA (Magalhães et al., 2005), DNA modification through modulation of sirtuin Sirt1 activity (Lin et al., 2004), decreased rates of oxidation reactions such as glycolysis or Glu/Gln oxidation (McKenna, 2007), and a further decrease in ATP production (Pettit et al., 1975). Because FA synthesis consumes two hydrogens from reduced cofactors for each 2 carbons incorporated, we hypothesize that FA synthesis may have a role as a hydrogen acceptor from reduced cofactors under hypoxia, thus maintaining cellular reduction potential.

To address this hypothesis, we applied a previously validated in-vitro model for neuronal hypoxia using SH-SY5Y cells exposed to $19 \%$ (normoxia) or $1 \%$ (hypoxia) oxygen levels (Brose et al., 2014). FA synthesis was inhibited at two different steps in the biosynthetic pathway using tetradecyloxy-2-furoic acid (TOFA, inhibits Acetyl-CoA carboxylase Loftus et al., 2000) and cerulenin (inhibits FA synthase, Heiligtag et al., 2002; Lupu and Menendez, 2006). FA synthesis inhibition significantly increased $\mathrm{NADH}_{2}^{+} / \mathrm{NAD}^{+}$and $\mathrm{NADPH}_{2}^{+} / \mathrm{NADP}^{+}$ ratios under hypoxia and resulted in increased lactic acid under both normoxic and hypoxic conditions. Importantly, FA synthesis inhibition caused cytotoxicity under hypoxia but not normoxia. These results indicate that FA may serve as hydrogen acceptors under hypoxia, thus supporting oxidation reaction including anaerobic glycolysis. These findings may help to identify a radically different approach to attenuate hypoxia related pathophysiology in the nervous system including stroke.

\section{MATERIALS AND METHODS}

\section{Materials}

SH-SY5Y cells were a gift from Dr. Colin Combs. All culture media and horse serum were purchased from Life Technologies (Grand Island, NY, USA). Fetal bovine serum (FBS) was purchased from Serum Source International (Charlotte, NC, USA). L-[U $\left.{ }^{14} \mathrm{C}\right]$ glutamaic acid $(260 \mathrm{mCi} / \mathrm{mmol})$ was purchased from PerkinElmer (Waltham, MA, USA). TOFA and cerulenin were purchased from Cayman Chemical (Ann Arbor, MI, USA). All other chemicals and solvents used were purchased from Fisher Scientific (Waltham, MA USA) and were LC-MS grade.

\section{Cell Culture and Hypoxic Treatment}

Cells were plated 3 days before the experiment on a six-well plate (Cellstar, Griner Bio-One, Monroe, NC, USA) at a density of 1.5 million cells per well. The cells were grown in Dulbecco's modified Eagle medium with nutrient mixture F-12 (DMEM/F12) with $10 \% \mathrm{FBS}$ and $5 \%$ horse serum at $37^{\circ} \mathrm{C}$ and $5 \% \mathrm{CO}_{2}$.

The hypoxic treatment was as described earlier (Brose et al., 2014). Briefly, the cells were preconditioned by replacing the growth medium with serum-free minimum essential media (MEM) and incubating in $19 \% \mathrm{O}_{2}$ (Normoxia) or $1 \% \mathrm{O}_{2}$ (Hypoxia) in $5 \% \mathrm{CO}_{2}$ at $37^{\circ} \mathrm{C}$ using nitrogen gas to purge the oxygen. After $24 \mathrm{~h}$, the media was replaced with $2 \mathrm{~mL}$ of fresh serum-free MEM containing radiolabeled tracer $\left(2 \mu \mathrm{Ci}\left[\mathrm{U}_{-}{ }^{14} \mathrm{C}\right.\right.$ Glu]) and/or fatty acid synthesis inhibitor (TOFA, $2 \mu \mathrm{g} / \mathrm{mL}$; cerulenin, $1 \mu \mathrm{g} / \mathrm{mL}$ ) and returned to their respective incubation conditions for another $18 \mathrm{~h}$. A short re-oxygenation during media change did not significantly affect the FA synthesis rate as was estimated using de-oxygenated media (data not shown).

\section{Lipid Extraction and Saponification}

To measure incorporation of radiotracer into fatty acids, cellular lipids were extracted and saponified as described earlier (Brose et al., 2014). Briefly, the media was removed and the cells were washed twice with ice-cold phosphate buffered saline. After removing the final wash, $0.5 \mathrm{~mL}$ of methanol was added to the cells; they were scraped and transferred into a silanized with Sigmacote (Sigma Chemical Co., St. Louis, MO) screw top glass tube. Another, $0.5 \mathrm{~mL}$ of methanol was added, the plates were scraped again, and the solution was combined with the methanol solution. A Folch extract (Folch et al., 1957) was performed by adding an additional $1 \mathrm{~mL}$ of methanol and $4 \mathrm{~mL}$ chloroform. The mixture was soniciated using a probe sonicator (Model 150 Sonic Dismembrator, Fisher Scientific) and centrifuged at $2000 \times \mathrm{g}$ for $10 \mathrm{~min}$. The supernatant was transferred into a new silanized screw top glass tube and was washed with 1.2 $\mathrm{mL}$ saline ( $0.9 \%$ sodium chloride). The extract was washed an additional two times with $1.2 \mathrm{~mL}$ chloroform:methanol:water (3:48:47). The extract was dried under nitrogen, re-dissolved in the saponification solution $(180 \mu \mathrm{L}$ methanol and $20 \mu \mathrm{l} 5 \mathrm{M}$ potassium hydroxide in water) and heated to $60^{\circ} \mathrm{C}$ for $60 \mathrm{~min}$ to saponify. The samples were then neutralized with $20 \mu \mathrm{L} 5 \mathrm{M}$ hydrochloric acid in water. After neutralization, $780 \mu \mathrm{L}$ of saline was added and the fatty acids were extracted with $2 \mathrm{~mL}$ hexane three times. The combined hexane extracts were evaporated and the fatty acids were re-dissolved in $1 \mathrm{~mL}$ of hexane. Radioactivity of an aliquot of the samples was measured in $10 \mathrm{~mL}$ Cytoscint (MP Biomedicals; Solon, OH, USA) using a scintillation counter (LS-6500, Beckman Coulter, Pasadena, CA, USA).

\section{Cytotoxicity}

Cytotoxicity was measured as a percent of lactate dehydrogenase $(\mathrm{LDH})$ released from the cells into the media using an enzymatic kit (BioVision, Milpitas, CA, USA). Media was collected, and the cells were lysed in $1 \mathrm{~mL}$ of the included lysis buffer. For both media and cell lysate, $10 \mu \mathrm{L}$ was used for LDH measurement. Absorbance was measured at $450 \mathrm{~nm}$ using a Flexstation III plate 
reader (Molecular Devices; Sunnyvale, CA, USA). LDH released was calculated as $\left(\mathrm{LDH}_{\text {medium }} / \mathrm{LDH}_{\text {medium+cells }}\right) \times 100 \%$.

\section{Lactic Acid}

Lactic acid was measured using $20 \mu \mathrm{L}$ of media with a fluorescence-based enzymatic kit from Cayman Chemical. Fluorescence was measured with a Flexstation III plate reader using an excitation wavelength of $535 \mathrm{~nm}$ and an emission wavelength of $590 \mathrm{~nm}$ with a cutoff filter of $570 \mathrm{~nm}$.

\section{$\mathrm{NAD}^{+} / \mathrm{NADH}_{2}$ and $\mathrm{NADP}^{+} / \mathrm{NADPH}_{2}$ Measurement}

Nucleotides were extracted from cells under ice-cold conditions by adding ice-cold $0.5 \mathrm{~mL}$ methanol:water (80:20) containing $0.1 \mathrm{mg} / \mathrm{mL}$ ethylenediaminetetraacetic acid and scraping the cells. The solution containing cells was transferred to a $1.5 \mathrm{~mL}$ microcentrifuge tube. Another $0.5 \mathrm{~mL}$ of the methanol:water solution was added to each well, the wells were scraped again, and the wash was combined with the previous wash. The combined solutions were sonicated, centrifuged at $10000 \times \mathrm{g}$ for $10 \mathrm{~min}$ at $4^{\circ} \mathrm{C}$. The supernatant was transferred into a 2 $\mathrm{mL}$ microcentrifuge tube and was washed from lipids with 1 $\mathrm{mL}$ hexane 2 times. The remaining solution was evaporated in a vacuum concentrator. The residue was redissolved in $20 \mu \mathrm{L}$ water and transferred into a silanized microvial insert (Microsolv, Eatontown, NJ USA part number 9502S-02ND) and $10 \mu \mathrm{L}$ was injected into the LC-MS.

Nucleotides were separated on the same day using a HYPERCARB column $(3 \mu \mathrm{m}, 250 \AA, 150 \times 2.1 \mathrm{~mm}$; Thermo Fisher Scientific; Waltham, MA, USA) maintained at room temperature. The LC system was a Waters AQUITY UPLC pump and a well plate autosampler (Waters; Milford, MA, USA). The autosampler temperature was $8^{\circ} \mathrm{C}$. Solvent A consisted of water containing $2 \mathrm{mM}$ ammonium acetate at $\mathrm{pH} 10$ and solvent $\mathrm{B}$ consisted of acetonitrile containing $2 \mathrm{mM}$ ammonium acetate at $\mathrm{pH} 10$. The flow rate was $0.3 \mathrm{~mL} / \mathrm{min}$ and the initial conditions were $97 \% \mathrm{~A}$ and $3 \% \mathrm{~B}$. The initial conditions were held for $0.5 \mathrm{~min}$. B was increased to $10 \%$ over $8 \mathrm{~min}$ and held for $2 \mathrm{~min}$. B was then further increased to $25 \%$ over $2 \mathrm{~min}$ and held for $4 \mathrm{~min}$. Finally, B was increased to $98 \%$ over 4 min and held for $7.5 \mathrm{~min}$. B was then returned to the initial conditions over $0.5 \mathrm{~min}$ and held for $2 \mathrm{~min}$.

Quantification of nucleotides was performed on a Waters Synapt G2-S quadrupole time-of-flight mass spectrometer (Q-TOF). The electrospray ionization was in negative ion mode as previously described (Brose et al., 2013). The cone voltage was $20 \mathrm{~V}$ with a capillary voltage of $1.51 \mathrm{kV}$. The source temperature was $110^{\circ} \mathrm{C}$. The desolvation temperature was $350^{\circ} \mathrm{C}$. The cone gas flow was $10 \mathrm{~L} / \mathrm{h}$, the desolvation gas flow was $1000 \mathrm{~L} / \mathrm{h}$ and the nebulizer gas was 6bar. The analyzer was operated in the centroid sensitivity mode with an extended dynamic range with a resolution of 10,000. Mass correction was performed using leucine enkephalin $(400 \mathrm{pg} / \mu \mathrm{L}, \mathrm{ACN}$ : water, 50: 50) which was infused at $10 \mu \mathrm{L} / \mathrm{min}$. The acquisition rate was 10 hertz. $\mathrm{NAD}^{+}, \mathrm{NADH}_{2}^{+}, \mathrm{NADP}^{+}$, and $\mathrm{NADPH}_{2}^{+}$were quantified using $\mathrm{m} / \mathrm{z} 662.1013,664.1161,742.0670$, and 744.0833
Da, respectively. Instrument control, acquisition, and sample analysis was performed using MassLynx V4.1 software (Waters).

\section{Statistics}

Statistical comparisons were determined using an ANOVA with Tukey's post-hoc test. Statistical significance was defined as $<0.05$. Values are expressed as mean \pm SD. GraphPad Prism 6 (GraphPad; San Diego, CA) software was used for statistical analysis.

\section{RESULTS}

To address the role for increased FA synthesis under hypoxia, we use our previously validated model for neuronal cell hypoxia (Brose et al., 2014). Consistent with our previous results, FA synthesis from Glu was dramatically 6.4-fold increased in SHSY5Y cells under $1 \% \mathrm{O}_{2}$ (Figure 1). Next, we inhibited FA synthesis at the Acetyl-CoA carboxylase (TOFA, Loftus et al., 2000) or FA synthase (cerulenin, Heiligtag et al., 2002; Lupu and Menendez, 2006) reactions. The inhibitors TOFA and cerulenin were used at concentrations 5 - and 3-fold above their IC $_{50}$ values, respectively (Zhu et al., 2004; Wu et al., 2011), and significantly inhibited FA synthesis from Glu under both normoxic and hypoxic conditions (Figures 1A,B) while they were not toxic under normoxia (Figure 1C). Importantly, at the concentrations used, TOFA demonstrated a higher potency to inhibit FA synthesis under both normoxia (5.1-fold FA synthesis inhibition by TOFA compared to 1.7 -fold inhibition by cerulenin) and hypoxia (8.1-fold FA synthesis inhibition by TOFA compared to 2.2-fold inhibition by cerulenin) (Figures 1A,B).

To assay the effect of FA synthesis inhibition on cellular reduction potential, we applied a high resolution accurate mass LC-MS approach to measure $\mathrm{NADH}_{2}^{+} / \mathrm{NAD}^{+}$and $\mathrm{NADPH}_{2}^{+} / \mathrm{NADP}^{+}$ratios under normoxia and hypoxia (Figure 2). In the control (vehicle treated) cells, hypoxia resulted in an increased $\mathrm{NADH}_{2}^{+} / \mathrm{NAD}^{+}$ratio in both TOFA and cerulenin experiments. This is consistent with hypoxic conditions when $\mathrm{O}_{2}$ levels are insufficient to accept $\mathrm{H}_{2}$ from reduced cofactors through the electron transport chain. Slight differences in the $\mathrm{NADH}_{2}^{+} / \mathrm{NAD}^{+}$and $\mathrm{NADPH}_{2}^{+} / \mathrm{NADP}^{+}$ ratios between experiments may be attributed to the differences between culture age and density because TOFA and cerulenin experiments were performed at different times, and the $\mathrm{NADH}_{2}^{+} / \mathrm{NAD}^{+}$ratio is closely linked to physiological and pathological states (Schwartz et al., 1974; Atzori et al., 1990; Zhang et al., 2006; Sun et al., 2012). Surprisingly, hypoxia decreased $\mathrm{NADPH}_{2}^{+} / \mathrm{NADP}^{+}$ratio. This is consistent with previous reports (Tribble and Jones, 1990; Gupte and Wolin, 2006; Kathagen-Buhmann et al., 2016) and may be associated with the depression of pentose-phosphate pathway (Gupte and Wolin, 2006; Kathagen-Buhmann et al., 2016). Alternatively, decreased $\mathrm{NADPH}_{2}^{+}$under hypoxia may be explained through significant increased FA synthesis that utilizes $\mathrm{NADPH}_{2}^{+}$as a cofactor.

Consistent with our hypothesis, both inhibitors significantly increased both $\mathrm{NADH}_{2}^{+} / \mathrm{NAD}^{+}$and $\mathrm{NADPH}_{2}^{+} / \mathrm{NADP}^{+}$ratios under hypoxia as compared to vehicle treated hypoxic cells 

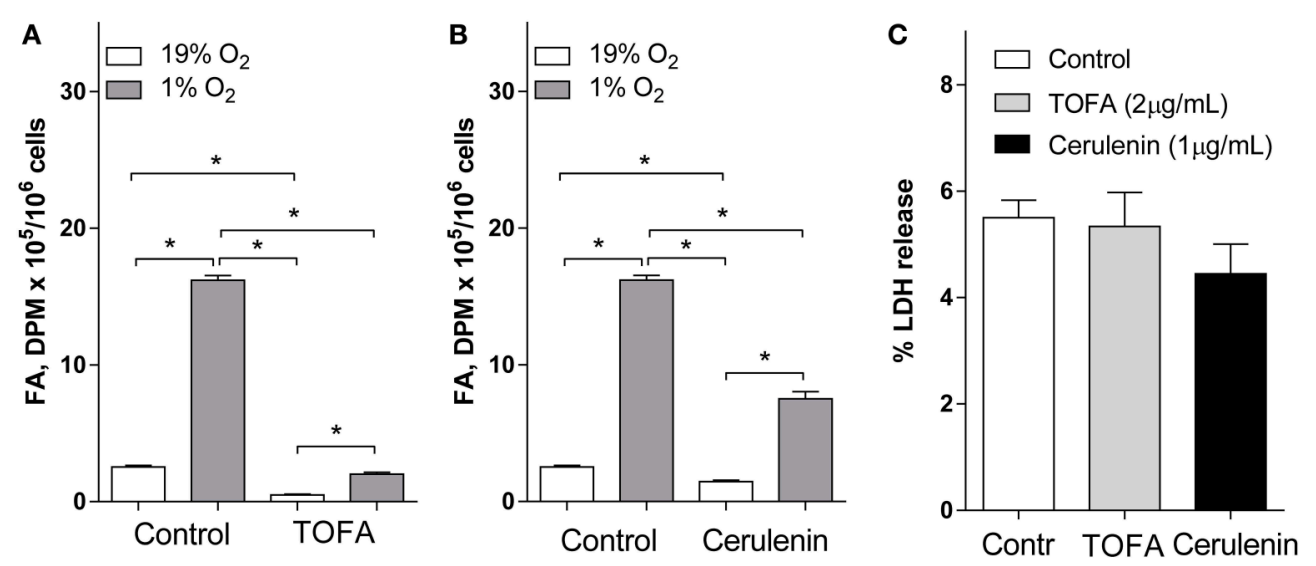

FIGURE 1 | Fatty acid synthesis from glutamate in SH-SY5Y cells was inhibited by TOFA and cerulenin under normoxia (19\% $\mathrm{O}_{2}$ ) and hypoxia (1\% $\left.\mathrm{O}_{2}\right)$ and did not cause toxicity under normoxia. (A,B): SH-SY5Y cells were preconditioned in serum-free MEM for $24 \mathrm{~h}$ under normoxia or hypoxia. The media was replaced with a fresh media and the cells were pretreated with vehicle (control, $1 \mu \mathrm{L} / \mathrm{mL}$ DMSO), (A) TOFA (2 $\mu \mathrm{g} / \mathrm{mL})$, or (B) cerulenin (1 $\mu \mathrm{g} / \mathrm{mL})$ for $30 \mathrm{~min}$. [U- $\left.{ }^{14} \mathrm{C}\right]$ glutamate $(2 \mu \mathrm{Ci})$ was then added to the wells. The cells were incubated for another $18 \mathrm{~h}$ under normoxia or hypoxia. Fatty acid (FA) radioactivity was determined as described in the Materials and Methods. (C): Percent of $\mathrm{LDH}$ released into the media was measured under normoxic (19\% $\mathrm{O}_{2}$ ) conditions to confirm the inhibitors TOFA $(2 \mu \mathrm{g} / \mathrm{mL})$ and cerulenin $(1 \mu \mathrm{g} / \mathrm{mL})$ were not toxic at the concentrations used. ${ }^{*}$-significantly different, $p<0.05$. Values are mean $\pm \mathrm{SD}, n=3$.

(Figure 2). Similar to the effect on FA synthesis, TOFA had a stronger effect on $\mathrm{NADH}_{2}^{+} / \mathrm{NAD}^{+}$ratios $(1.8$-fold increase as compared to vehicle treated hypoxic cells) as compared to cerulenin (1.3-fold increase), while the effect on $\mathrm{NADPH}_{2}^{+} / \mathrm{NADP}^{+}$ratios was similar for both inhibitors $(\sim 3-$ fold increase as compared to vehicle treated hypoxic cells).

Because the $\mathrm{NADH}_{2}^{+} / \mathrm{NAD}^{+}$ratio is closely related to anaerobic glycolysis and lactic acidosis which are both activated under 1\% hypoxia (Zhang et al., 2006), we assayed the effect of FA synthesis inhibition with TOFA on media lactic acid (Figure 3A). Consistent with anaerobic glycolysis activation under hypoxia, $1 \% \mathrm{O}_{2}$ increased media lactic acid 1.9-fold. TOFA did not have an effect on lactic acid under normoxia, but significantly increased lactate under hypoxia 2.6-fold as compared to vehicle treated hypoxic cells (Figure 3A). Consistent with increased $\mathrm{NADH}_{2}^{+} / \mathrm{NAD}^{+}$and $\mathrm{NADPH}_{2}^{+} / \mathrm{NADP}^{+}$ratios, and increased lactoacidosis under hypoxia, TOFA dramatically increased cytotoxicity under hypoxia but not normoxia as measured by cellular LDH release (Figure 3B).

\section{DISCUSSION}

Despite the significant contribution of brain hypoxia in the development of many of pathophysiological conditions, biochemical mechanisms for neuronal adaptation to hypoxia are still not completely understood. Previously, using both primary neurons and neuronal cell lines, we have reported a novel response of neuronal cells to hypoxia through a dramatic increase in FA synthesis from Gln/Glu (Brose et al., 2014). However, the biological importance for this pathway has not been addressed.

To explain the role for increased FA synthesis under neuronal hypoxia, we have previously hypothesized few mechanisms that may have a complimentary protective role, including balancing
Glu levels, protection against oxidative stress, and maintaining reduction potential with support of anaerobic glycolysis (Brose et al., 2014). In the current study, we have addressed the role for FA synthesis in supporting reduction potential as a potent acceptor of hydrogen under hypoxia.

The mechanism for alterations in reduction potential under hypoxia is well understood. Under hypoxia, hydrogen transfer from substrates to oxygen in the electron transport chain in mitochondria is decreased. This leads to accumulation of hydrogen on intermediate cofactors $\left(\mathrm{NADH}_{2}^{+}, \mathrm{NADPH}_{2}^{+}\right.$, $\mathrm{FADH}_{2}$; Garofalo et al., 1988; Obi-Tabot et al., 1993; Foster et al., 2005). Because the total pool of reduced and oxidized co-factors is unchanged, the level of oxidized cofactors is decreased, thus the ratio between reduced and oxidized cofactors is increased. As a result, ATP levels are decreased, while the reduced cofactors $\left(\mathrm{NADH}_{2}^{+}, \mathrm{NADPH}_{2}^{+}, \mathrm{FADH}_{2}\right)$ are significantly increased, limiting energy production and increasing reduced/oxidized cofactor ratio in cells. In addition, cells are unable to completely oxidize pyruvate and acetyl-CoA produced in glycolysis and glutaminolysis (McKenna, 2007). In line with this mechanism, and consistent with previous studies when $1 \% \mathrm{O}_{2}$ was used to model hypoxia (Zhang et al., 2006), we observed a significant increase in the $\mathrm{NADH}_{2}^{+} / \mathrm{NAD}^{+}$ ratio and lactic acid accumulation in control hypoxic cells (Figures 2, 3). However, similar to previous reports (Tribble and Jones, 1990; Gupte and Wolin, 2006; Kathagen-Buhmann et al., 2016), hypoxia decreased the $\mathrm{NADPH}_{2}^{+} / \mathrm{NADP}^{+}$ratio (Figure 2) which may be explained through the depression of the pentosephosphate pathway(Gupte and Wolin, 2006; Kathagen-Buhmann et al., 2016). Alternatively, decreased $\mathrm{NADPH}_{2}^{+}$under hypoxia may be explained through significantly increased FA synthesis under hypoxia since FA synthesis utilizes $\mathrm{NADPH}_{2}^{+}$as a cofactor. Astrocytes and, to a lesser extent, neurons adapt to hypoxic conditions through switching to anaerobic glycolysis. However, 

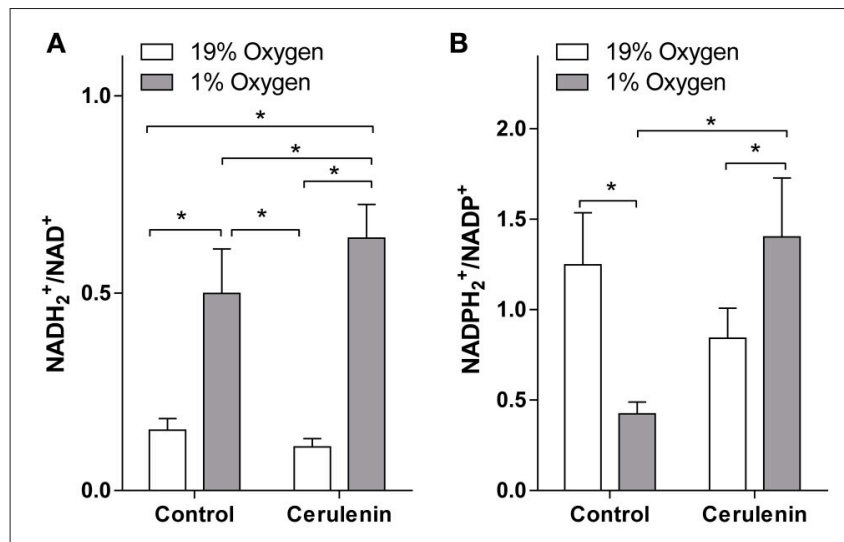

C

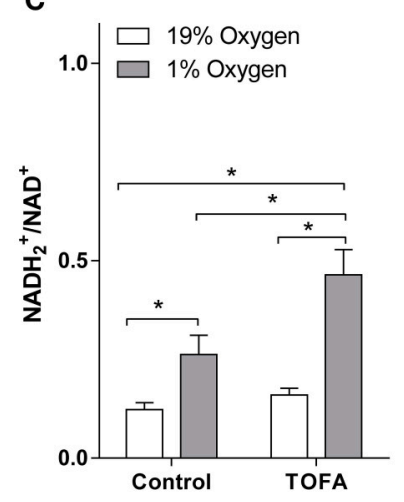

D

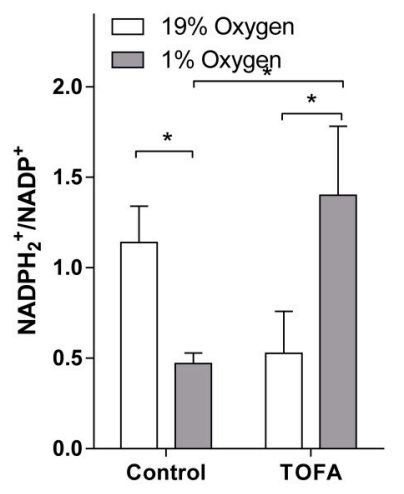

FIGURE 2 | $\mathrm{NADH}_{2}^{+} / \mathrm{NAD}^{+}$and $\mathrm{NADPH}_{2}^{+} / \mathrm{NADP}^{+}$levels under hypoxia are increased with fatty acid synthesis inhibition. Inhibition of fatty acid synthesis in hypoxic SH-SY5Y cells increases the amounts of $\mathrm{NADH}_{2}^{+}(\mathbf{A}, \mathbf{C})$ and $\mathrm{NADPH}_{2}^{+} \mathbf{( B , D )}$ relative to their oxidized forms. SH-SY5Y cells were preconditioned in serum-free MEM for $24 \mathrm{~h}$ under normoxia or hypoxia. The media was switched to a fresh media and the cells were treated with vehicle (control, $1 \mu \mathrm{L} / \mathrm{mL}$ DMSO), cerulenin $(1 \mu \mathrm{g} / \mathrm{mL})$ (A,B), or TOFA $(2 \mu \mathrm{g} / \mathrm{mL})$ (C,D) and were incubated for another $18 \mathrm{~h}$ under normoxia or hypoxia. Nucleotides were extracted with 80:20 methanol: water containing EDTA and were analyzed with LC-MS as described in the Materials and Methods.

${ }^{*}$-significantly different, $p<0.05$. Values are mean $\pm \mathrm{SD}, n=3$.

under hypoxia anaerobic glycolysis leads to further accumulation of both reduced cofactors and lactic acid (Figure 3). This is consistent with attenuation of $\mathrm{NADH}_{2}^{+}$accumulation under hypoxia when glucose levels are decreased (Garofalo et al., 1988).

The altered reduction potential has several devastating effects on cells. It results in: 1. Further lactate accumulation (as an alternative acceptor of hydrogen), and $\mathrm{pH}$ drop (Payen et al., 1996; Malisza et al., 1999; Zhang et al., 2006). Importantly, even under normoxia, astrocytic lactate production is very high to provide this key metabolite to neurons for energy metabolism (Hu and Wilson, 1997; Galeffi et al., 2007). Under hypoxia, neuronal oxidative potential is limited, decreasing lactate utilization; 2. Reactive oxygen species formation with consequential damage to lipids, proteins, and DNA (Magalhães et al., 2005). This paradoxical phenomenon of hypoxia-induced oxidative stress is explained through increased mitochondrial reductive stress (Turrens et al., 1985; Duranteau et al., 1998).
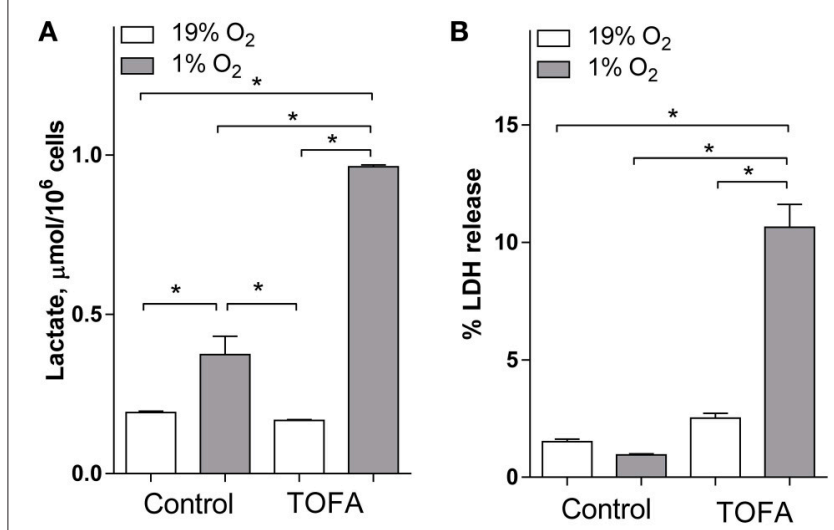

FIGURE 3 | Inhibition of fatty acid synthesis with TOFA in SH-SY5Y cells increases lactic acid levels and toxicity under hypoxia. SH-SY5Y cells were preconditioned in serum-free MEM for $24 \mathrm{~h}$ under normoxia or hypoxia. The media was switched to a fresh media and the cells were treated with vehicle (control, $1 \mu \mathrm{L} / \mathrm{mL}$ DMSO) or TOFA ( $2 \mu \mathrm{g} / \mathrm{mL}$ ). The cells were incubated for another $18 \mathrm{~h}$ under normoxia or hypoxia. (A): Lactic acid was measured using an enzymatic fluorescent kit. (B): Toxicity was determined through percent of $\mathrm{LDH}$ release which was measured using a colorimetric enzymatic kit. *significantly different, $p<0.05$. Values are mean $\pm \mathrm{SD}, n=3$.

One of the additional mechanisms for increased oxidative damage under accumulation of $\mathrm{NADH}_{2}^{+}$is the formation of $\mathrm{H}_{2} \mathrm{O}_{2}$ that promotes reactive oxygen species formation (Circu and $\mathrm{Aw}, 2010)$. Intriguingly, the $\mathrm{NADPH}_{2}^{+}$to $\mathrm{NADP}^{+}$ratio is decreased under hypoxia as we discussed above (Figure 2). This may cause additional oxidative damage due to involvement of $\mathrm{NADPH}_{2}^{+}$in enzymatic detoxification of reactive oxygen species. However, because an active mitochondrial FA synthase may use $\mathrm{NADH}_{2}^{+}$as a cofactor (Podack and Seubert, 1972; Seubert and Podack, 1973; Hinsch and Seubert, 1975; Whereat and Rabinowitz, 1975; Hinsch et al., 1976; Hiltunen et al., 2010; Smith et al., 2012) and $\mathrm{H}_{2}$ is readily transferred from $\mathrm{NADH}_{2}^{+}$to $\mathrm{NADP}^{+}$by transhydrogenases (Bizouarn et al., 2000; Jackson et al., 2002), increased FA synthesis may not cause but rather protect against oxidative damage; 3. Altered gene expression and protein modifications through increased protein acetylation. The $\mathrm{NADH}_{2}^{+} / \mathrm{NAD}^{+}$ratio modulates the activity of the NAD-dependent deacetylase sirtuin Sirt1 (Lin et al., 2004) that plays a central role in the regulation of thousands of metabolic enzymes and transcription factors in the cytosol and mitochondria (Hallows et al., 2006; Herranz and Serrano, 2010; Wang et al., 2010; Zhao et al., 2010; Hirschey et al., 2011); 4. Decreased rates of oxidation metabolic reactions including the glycolytic pathway. Because over 700 oxidoreduction enzymes use $\mathrm{NAD}^{+}$or $\mathrm{NADP}^{+}$as cofactors (Sun et al., 2012), the reduced availability of oxidized $\mathrm{NAD}^{+}$and $\mathrm{NADP}^{+}$globally effects cellular biochemical processes; 5 . In addition, the altered reduction potential further reduces ATP production (Pettit et al., 1975), causing neuronal damage. Few mechanisms are involved in the reduction of ATP production including allosteric regulation and oxidized cofactor availability.

Because FA synthesis consumes $\mathrm{H}_{2}$ from two $\mathrm{NADPH}_{2}^{+}$ per each acetyl-CoA incorporated into FA chain, $\mathrm{H}_{2}$ is readily 
transferred from $\mathrm{NADH}_{2}^{+}$to $\mathrm{NADP}^{+}$by transhydrogenases (Bizouarn et al., 2000; Jackson et al., 2002), and an active mitochondrial FA synthase may use $\mathrm{NADH}_{2}^{+}$as a cofactor (Podack and Seubert, 1972; Seubert and Podack, 1973; Hinsch and Seubert, 1975; Whereat and Rabinowitz, 1975; Hinsch et al., 1976; Hiltunen et al., 2010; Smith et al., 2012), we hypothesized that increased FA synthesis under hypoxia has a role in maintaining cellular reduction potential. Importantly, under hypoxia each acetyl-CoA produced from glucose also produces two $\mathrm{NADH}_{2}^{+}$. One is produced during anaerobic glycolysis, and another one during pyruvate oxidative decarboxylation. Thus, activation of FA synthesis will stoichiometrically use all $\mathrm{NADH}_{2}^{+}$produced in the anaerobic glycolysis and will prevent hydrogen accumulation in the form of lactic acid. In addition, it will support Glu oxidation also associated with $\mathrm{NAD}(\mathrm{P}) \mathrm{H}_{2}^{+}$ formation (McKenna, 2007). Using a loss of function approach through inhibition of FA synthesis at two different metabolic reactions at not-cytotoxic levels, we demonstrated a dramatic increase in $\mathrm{NADH}_{2}^{+} / \mathrm{NAD}^{+}$and $\mathrm{NADPH}_{2}^{+} / \mathrm{NADP}^{+}$ratios under hypoxia compared to vehicle-treated hypoxic neuronal cells (Figure 2).

FA synthesis inhibition also resulted in the increased lactic acid levels, and caused a significant toxicity under hypoxia but not normoxia (Figure 3). Because TOFA may alter a number of different pathways, it is difficult to provide a conclusive interpretation of the toxicity mechanism of fatty acid inhibition under hypoxia. However, because reductive potential was increased with both inhibitors under hypoxia, and increased

\section{REFERENCES}

Atzori, L., Dypbukt, J. M., Sundqvist, K., Cotgreave, I., Edman, C. C., Moldéus, P., et al. (1990). Growth-associated modifications of low-molecular-weight thiols and protein sulfhydryls in human bronchial fibroblasts. J. Cell. Physiol. 143, 165-171. doi: $10.1002 /$ jcp. 1041430123

Bizouarn, T., Fjellström, O., Meuller, J., Axelsson, M., Bergkvist, A., Johansson, C., et al. (2000). Proton translocating nicotinamide nucleotide transhydrogenase from E. coli. Mechanism of action deduced from its structural and catalytic properties. Biochim. Biophys. Acta 1457, 211-228. doi: 10.1016/S0005-2728(00)00103-1

Brose, S. A., Marquardt, A. L., and Golovko, M. Y. (2014). Fatty acid biosynthesis from glutamate and glutamine is specifically induced in neuronal cells under hypoxia. J. Neurochem. 129, 400-412. doi: 10.1111/jnc. 12617

Brose, S., Baker, A., and Golovko, M. (2013). A fast one-step extraction and UPLC$\mathrm{MS} / \mathrm{MS}$ analysis for E2/D2 series prostaglandins and isoprostanes. Lipids 48, 411-419. doi: 10.1007/s11745-013-3767-5

Circu, M. L., and Aw, T. Y. (2010). Reactive oxygen species, cellular redox systems, and apoptosis. Free Radic. Biol. Med. 48, 749-762. doi: 10.1016/j.freeradbiomed.2009.12.022

Clambey, E. T., McNamee, E. N., Westrich, J. A., Glover, L. E., Campbell, E. L., Jedlicka, P., et al. (2012). Hypoxia-inducible factor-1 alpha-dependent induction of FoxP3 drives regulatory T-cell abundance and function during inflammatory hypoxia of the mucosa. Proc. Natl. Acad. Sci. U.S.A. 109, e2784e2793. doi: 10.1073/pnas.1202366109

Duranteau, J., Chandel, N. S., Kulisz, A., Shao, Z., and Schumacker, P. T. (1998). Intracellular signaling by reactive oxygen species during hypoxia in cardiomyocytes. J. Biol. Chem. 273, 11619-11624. doi: $10.1074 /$ jbc.273.19.11619 reductive potential is the cause but not a direct result of apoptosis (Circu and Aw, 2010; Redza-Dutordoir and Averill-Bates, 2016), we speculate that decreased consumption of reduced cofactors in fatty acid synthesis pathway through inhibition may lead to cellular death under hypoxia.

Together, these data strongly indicate that FA synthesis is important for maintaining reduction potential and decreasing lactic acid, in order to support cell survival under hypoxia. These findings may help to identify a radically different approach to attenuate hypoxia related pathophysiology in the nervous system including stroke.

\section{AUTHOR CONTRIBUTIONS}

SB: Conducted experiments, participated in designing the study and method development, writing and editing the manuscript, analyzed and interpreted the data. SG: Conducted MS experiments, participated in LC-MS method development and MS data analysis and interpretation. MG: Supervised and designed the study and method development, wrote and edited the manuscript, analyzed and interpreted the data.

\section{FUNDING}

This publication was made possible by NIH Grant 1R01AG042819-04 (MG), NIH funded COBRE Mass Spec Core Facility Grant 1P30GM103329-04 (MG), and UND Office of the Vice President for Research funds (MG).

Folch, J., Lees, M., and Sloan Stanley, G. H. (1957). A simple method for the isolation and purification of total lipides from animal tissues. J. Biol. Chem. 226, 497-509.

Foster, K. A., Beaver, C. J., and Turner, D. A. (2005). Interaction between tissue oxygen tension and $\mathrm{NADH}$ imaging during synaptic stimulation and hypoxia in rat hippocampal slices. Neuroscience 132, 645-657. doi: 10.1016/j.neuroscience.2005.01.040

Galeffi, F., Foster, K. A., Sadgrove, M. P., Beaver, C. J., and Turner, D. A. (2007). Lactate uptake contributes to the $\mathrm{NAD}(\mathrm{P}) \mathrm{H}$ biphasic response and tissue oxygen response during synaptic stimulation in area CA1 of rat hippocampal slices. J. Neurochem. 103, 2449-2461. doi: 10.1111/j.1471-4159.2007.04939.x

Gallagher, S. A., and Hackett, P. H. (2004). High-altitude illness. Emerg. Med. Clin. North Am. 22, 329-355. doi: 10.1016/j.emc.2004.02.001

Garofalo, O., Cox, D. W., and Bachelard, H. S. (1988). Brain levels of NADH and $\mathrm{NAD}+$ under hypoxic and hypoglycaemic conditions in vitro. J. Neurochem. 51, 172-176. doi: 10.1111/j.1471-4159.1988.tb04851.x

Gupte, S. A., and Wolin, M. S. (2006). Hypoxia promotes relaxation of bovine coronary arteries through lowering cytosolic NADPH. Am. J. Phys. Heart Circ. Physiol. 290, H2228-H2238. doi: 10.1152/ajpheart.00615.2005

Hallows, W. C., Lee, S., and Denu, J. M. (2006). Sirtuins deacetylate and activate mammalian acetyl-CoA synthetases. Proc. Natl. Acad. Sci. U.S.A. 103, 10230-10235. doi: 10.1073/pnas.0604392103

Heiligtag, S. J., Bredehorst, R., and David, K. A. (2002). Key role of mitochondria in cerulenin-mediated apoptosis. Cell Death Differ. 9, 1017-1025. doi: $10.1038 /$ sj.cdd. 4401055

Herranz, D., and Serrano, M. (2010). SIRT1: recent lessons from mouse models. Nat. Rev. Cancer 10, 819-823. doi: 10.1038/nrc2962

Hiltunen, J. K., Autio, K. J., Schonauer, M. S., Kursu, V. A., Dieckmann, C. L., and Kastaniotis, A. J. (2010). Mitochondrial fatty acid synthesis and respiration. Biochim. Biophys. Acta 1797, 1195-1202. doi: 10.1016/j.bbabio.2010.03.006 
Hinsch, W., Klages, C., and Seubert, W. (1976). On the mechanism of malonyl CoA independent fatty acid synthesis. Different properties of the mitochondrial chain elongation and enoyl CoA reductase in various tissues. Eur. J. Biochem. 64, 45-55. doi: 10.1111/j.1432-1033.1976.tb10273.x

Hinsch, W., and Seubert, W. (1975). On the mechanism of malonylcoa-independent fatty-acid synthesis. Eur. J. Biochem. 53, 437-447. doi: 10.1111/j.1432-1033.1975.tb04084.x

Hirschey, M. D., Shimazu, T., Capra, J. A., Pollard, K. S., and Verdin, E. (2011). SIRT1 and SIRT3 deacetylate homologous substrates: AceCS1,2 and HMGCS1,2. Aging 3, 635-642. doi: 10.18632/aging.100339

$\mathrm{Hu}, \mathrm{Y}$., and Wilson, G. S. (1997). A temporary local energy pool coupled to neuronal activity: fluctuations of extracellular lactate levels in rat brain monitored with rapid-response enzyme-based sensor. J. Neurochem. 69, 1484-1490. doi: 10.1046/j.1471-4159.1997.69041484.x

Jackson, J. B., White, S. A., Quirk, P. G., and Venning, J. D. (2002). The alternating site, binding change mechanism for proton translocation by transhydrogenase. Biochemistry 41, 4173-4185. doi: 10.1021/bi012078d

Kathagen-Buhmann, A., Schulte, A., Weller, J., Holz, M., Herold-Mende, C., Glass, R., et al. (2016). Glycolysis and the pentose phosphate pathway are differentially associated with the dichotomous regulation of glioblastoma cell migration versus proliferation. Neuro. Oncol. 18, 1219-1229. doi: 10.1093/neuonc/now024

Kirby, B. S., Crecelius, A. R., Voyles, W. F., and Dinenno, F. A. (2012). Impaired skeletal muscle blood flow control with advancing age in humans: attenuated atp release and local vasodilation during erythrocyte deoxygenation. Circ. Res. 111, 220-230. doi: 10.1161/CIRCRESAHA.112.269571

Lin, C., Wu, C. J., Wei, I. H., Tsai, M. H., Chang, N. W., Yang, T. T., et al. (2013). Chronic treadmill running protects hippocampal neurons from hypobaric hypoxia-induced apoptosis in rats. Neuroscience 231, 216-224. doi: 10.1016/j.neuroscience.2012.11.051

Lin, S. J., Ford, E., Haigis, M., Liszt, G., and Guarente, L. (2004). Calorie restriction extends yeast life span by lowering the level of NADH. Genes Dev. 18, 12-16. doi: $10.1101 /$ gad.1164804

Loftus, T. M., Jaworsky, D. E., Frehywot, G. L., Townsend, C. A., Ronnett, G. V., Lane, M. D., et al. (2000). Reduced food intake and body weight in mice treated with fatty acid synthase inhibitors. Science 288, 2379-2381. doi: $10.1126 /$ science.288.5475.2379

Lupu, R., and Menendez, J. A. (2006). Pharmacological inhibitors of fatty acid synthase (FASN)-catalyzed endogenous fatty acid biogenesis: a new family of anti-cancer agents? Curr. Pharm. Biotechnol. 7, 483-494. doi: $10.2174 / 138920106779116928$

Magalhães, J., Ascensão, A., Soares, J. M. C., Ferreira, R., Neuparth, M. J., Marques, F., et al. (2005). Acute and severe hypobaric hypoxia increases oxidative stress and impairs mitochondrial function in mouse skeletal muscle. J. Appl. Physiol. 99, 1247-1253. doi: 10.1152/japplphysiol.01324.2004

Malisza, K. L., Kozlowski, P., Ning, G., Bascaramurty, S., and Tuor, U. I. (1999). Metabolite changes in neonatal rat brain during and after cerebral hypoxia-ischemia: a magnetic resonance spectroscopic imaging study NMR Biomed. 12, 31-38. doi: 10.1002/(SICI)1099-1492(199902)12:1<31::AID-NBM544>3.0.CO;2-M

McKenna, M. C. (2007). The glutamate-glutamine cycle is not stoichiometric: fates of glutamate in brain. J. Neurosci. Res. 85, 3347-3358. doi: 10.1002/jnr.21444

Obi-Tabot, E. T., Hanrahan, L. M., Cachecho, R., Beer, E. R., Hopkins, S. R., Chan, J. C., et al. (1993). Changes in hepatocyte NADH fluorescence during prolonged hypoxia. J. Surg. Res. 55, 575-580. doi: 10.1006/jsre.1993.1187

Payen, J.-F., LeBars, E., Wuyam, B., Tropini, B., Pépin, J. L., Lévy, P., et al. (1996). Lactate Accumulation during Moderate Hypoxic Hypoxia in Neocortical Rat Brain. J. Cereb. Blood Flow Metab. 16, 1345-1352. doi: 10.1097/00004647-199611000-00032

Pettit, F. H., Pelley, J. W., and Reed, L. J. (1975). Regulation of pyruvate dehydrogenase kinase and phosphatase by acetyl-CoA/CoA and NADH/NAD ratios. Biochem. Biophys. Res. Commun. 65, 575-582. doi: 10.1016/S0006-291X(75)80185-9

Podack, E. R., and Seubert, W. (1972). On the mechanism of malonyl-CoA independent fatty acid synthesis. II. Isolation, properties and subcellular location of trans-2,3-hexenoyl-CoA and trans-2,3-decenoyl-CoA reductase. Biochim. Biophys. Acta 280, 235-247. doi: 10.1016/0005-2760(72)90090-2

Raymond, M., Li, P., Mangin, J. M., Huntsman, M., and Gallo, V. (2011). Chronic perinatal hypoxia reduces glutamate-aspartate transporter function in astrocytes through the janus kinase/signal transducer and activator of transcription pathway. J. Neurosci. 31, 17864-17871. doi: 10.1523/JNEUROSCI.3179-11.2011

Redza-Dutordoir, M., and Averill-Bates, D. A. (2016). Activation of apoptosis signalling pathways by reactive oxygen species. Biochim. Biophys. Acta 1863, 2977-2992. doi: 10.1016/j.bbamcr.2016.09.012

Schwartz, J. P., Passonneau, J. V., Johnson, G. S., and Pastan, I. (1974). The effect of growth conditions on NAD+ and NADH concentrations and the NAD+:NADH ratio in normal and transformed fibroblasts. J. Biol. Chem. 249, $4138-4143$.

Seubert, W., and Podack, E. R. (1973). Mechanisms and physiological roles of fatty acid chain elongation in microsomes and mitochondria. Mol. Cell Biochem. 1, 29-40. doi: 10.1007/BF01659936

Smith, S., Witkowski, A., Moghul, A., Yoshinaga, Y., Nefedov, M., de Jong, P., et al. (2012). Compromised mitochondrial fatty acid synthesis in transgenic mice results in defective protein lipoylation and energy disequilibrium. PLoS ONE 7:e47196. doi: 10.1371/journal.pone.0047196

Sun, F., Dai, C., Xie, J., and Hu, X. (2012). Biochemical issues in estimation of cytosolic free NAD/NADH ratio. PLoS ONE 7:e34525. doi: 10.1371/journal.pone.0034525

Tribble, D. L., and Jones, D. P. (1990). Oxygen dependence of oxidative stress. Rate of nadph supply for maintaining the GSH pool during hypoxia. Biochem. Pharmacol. 39, 729-736. doi: 10.1016/0006-2952(90)90152-b

Turrens, J. F., Alexandre, A., and Lehninger, A. L. (1985). Ubisemiquinone is the electron donor for superoxide formation by complex III of heart mitochondria. Arch. Biochem. Biophys. 237, 408-414. doi: 10.1016/0003-9861(85)90293-0

Wang, Q., Zhang, Y., Yang, C., Xiong, H., Lin, Y., Yao, J., et al. (2010). Acetylation of metabolic enzymes coordinates carbon source utilization and metabolic flux. Science 327, 1004-1007. doi: 10.1126/science.1179687

Whereat, A. F., and Rabinowitz, J. L. (1975). Aortic mitochondrial synthesis of lipid and its response to cholesterol feeding. Am. J. Cardiol. 35, 567-571. doi: 10.1016/0002-9149(75)90841-3

Wilson, M. H., Newman, S., and Imray, C. H. (2009). The cerebral effects of ascent to high altitudes. Lancet Neurol. 8, 175-191. doi: 10.1016/S1474-4422(09)70014-6

Wu, M., Singh, S. B., Wang, J., Chung, C. C., Salituro, G., Karanam, B. V., et al. (2011). Antidiabetic and antisteatotic effects of the selective fatty acid synthase (FAS) inhibitor platensimycin in mouse models of diabetes. Proc. Natl. Acad. Sci. U.S.A. 108, 5378-5383. doi: 10.1073/pnas.1002588108

Zhang, Q., Wang, S. Y., Nottke, A. C., Rocheleau, J. V., Piston, D. W., and Goodman, R. H. (2006). Redox sensor CtBP mediates hypoxiainduced tumor cell migration. Proc. Natl. Acad. Sci. U.S.A. 103, 9029-9033. doi: 10.1073/pnas.0603269103

Zhao, S., Xu, W., Jiang, W., Yu, W., Lin, Y., Zhang, T., et al. (2010). Regulation of cellular metabolism by protein lysine acetylation. Science 327, 1000-1004. doi: 10.1126/science.1179689

Zhu, G., Li, Y., Cai, X., Millership, J. J., Marchewka, M. J., and Keithly, J. S. (2004). Expression and functional characterization of a giant Type I fatty acid synthase (CpFAS1) gene from Cryptosporidium parvum. Mol. Biochem. Parasitol. 134, 127-135. doi: 10.1016/j.molbiopara.2003.11.011

Conflict of Interest Statement: The authors declare that the research was conducted in the absence of any commercial or financial relationships that could be construed as a potential conflict of interest.

Copyright (c) 2016 Brose, Golovko and Golovko. This is an open-access article distributed under the terms of the Creative Commons Attribution License (CC BY). The use, distribution or reproduction in other forums is permitted, provided the original author(s) or licensor are credited and that the original publication in this journal is cited, in accordance with accepted academic practice. No use, distribution or reproduction is permitted which does not comply with these terms. 